\title{
RESISTÊNCIAS CITADINAS: A REATIVAÇÃO E REOCUPAÇÃO DOS ESPAÇOS NA CAPITAL PERUANA
}

\author{
Indira Angela Eyzaguirre ${ }^{1}$
}

Data de submissão: 13.08 .2020

Data de aprovação: 02. 11. 2020

Peru foi um dos primeiros países da América Latina em declarar quarentena total em todo seu território, mas mesmo assim, atualmente é o sétimo pais com maior número de contagiados e falecidos, embora sua proporção territorial seja menor comparado com outros países. A cidade de Lima, capital peruana, é caracterizada por ser uma urbe ruidosa e uma das mais populosas, mas as dinâmicas citadinas mudaram e foram-se reorganizando a partir das imposições legislativas restritivas do poder executivo. Um país onde a maioria dos trabalhadores são informais e vivem do dia-dia, em que a ocupação das ruas e espaços citadinos é um símbolo de resistência e existência de forma cotidiana. A pandemia com certeza deixou muitos países devastados, e na capital limenha peruana não foi diferente. Este ensaio é produto do projeto fotográfico "Diario de cuarentena por las calles limeñas" que documenta a narrativa imagética da rotina citadina nas ruas do centro de Lima desde o começo da pandemia no Perú. Esta narrativa fotográfica retrata a procura da solidariedade e a adaptação para enfrentar estes tempos pandêmicos de alguns comerciantes e moradores de rua. Assim como documentar a resistência nos espaços reocupados nessa nova face da capital peruana, as fotografias foram tiradas com câmera de celular e foram cuidadosamente editadas com o aplicativo Adobe Lightroom.

Diversos grupos sociais estão reocupando os espaços na capital peruana, muitas pessoas ganharam o "bono universal" que é um tipo de bolsa que o governo ofereceu aos grupos mais vulneráveis para "subsistir" nestes tempos pandêmicos, muitas delas reocupam espaços fora dos bancos aguardando nas filas enquanto leem o jornal com notícias da reativação da economia peruana. Existiram "bonos" para quase todos os grupos sociais, menos para os chamados informais que são de pequeno porte ou microempreendedores. Entre os grupos que ganharam estas bolsas, estão as empresas de mediano e alto porte como os bares localizados no centro de Lima. Todos os bares e áreas de lazer citadino foram fechados quando chegou a pandemia, mas recentemente, muitos deles estão recomeçando em formato de restaurantes por delivery.

Toda a rotina citadina foi paralisada neste pais, como em outras partes do mundo, mas na capital peruana recentemente percebe-se a reocupação dos espaços de lazer como as praças onde os jovens, mas sobretudo os mais velhos vão para relaxar com uma leitura, aguardando o tempo passar em uma tarde cálida no inverno da cidade de Lima. Definitivamente, o processo de retomar esse direito à cidade é evidente nas ruas limenhas, como é perceptível na resistência dos moradores de rua, entre eles os chamados "jovens hippies", os mesmos que por todo este tempo "sumiram" das ruas. Mas com a reativação da cidade, eles voltam a resistir nos seus espaços, nas paradas dos semáforos, adaptando-se a uma nova rotina, a uma nova forma de segurança sanitária, a um "novo normal".

O que move esta cidade, é o comercio praticado pela classe trabalhadora, os espaços e direitos são renovados pelos mesmos cidadãos diante de tantas políticas restritivas. É assim que então, surgem os novos direitos a partir dessa classe resistente onde também surge a

\footnotetext{
${ }^{1}$ Mestre em Biologia na área de ecologia socioambiental. Escritora, fotógrafa e desenhadora freelance. Possuo diversas publicações de poemas, ensaios e artigos. Instituição/Afiliação Universidade Federal do Pará, Campus Bragança

${ }^{2}$ Projeto em processo de edição para ser publicado em: https://linktr.ee/indieyzaguirre.
} 
solidariedade citadina, principalmente a ajuda entre os trabalhadores de rua, os chamados de "ambulantes" ou "informais".

\begin{abstract}
O direito à vida urbana, transformada, renovada [...]. No seio dos efeitos sociais, devidos à pressão das massas [...]. Surgem direito [...] direitos das idades e dos sexos (mulher, a criança, o velho), direitos das condições (o proletário, o camponês), direitos à instrumentação e à educação, direito ao trabalho, à cultura, ao repouso, à saúde, à habitação. Apesar, ou através das gigantescas destruições [...]. A pressão da classe operaria foi e continua a ser necessária (mas não suficiente) para o reconhecimento desses direitos, para a sua entrada para os costumes, para a sua inscrição nos códigos, ainda bem incompletos. (LEFEBVRE, 2010, p. 116-117).
\end{abstract}

No meio destes direitos dos sexos, direitos de idades, surge a cooperatividade entre estes grupos, principalmente diante de possíveis "ameaças" neste ecossistema urbano. Estas possíveis ameaças vão desde o assédio do grupo militarizado que fiscaliza as ruas em prol da ordem e segurança sanitária e até o assédio da prensa que etiqueta aos informais como irresponsáveis ${ }^{3}$, por saírem às ruas vender seus produtos sem ter nenhum dever de segurança sanitária. Desta forma, estes chamados "informais" reagem de forma solidaria, ajudando-se entre eles, formando grupos pequenos, como os grupos de muitas mulheres que se comunicam entre elas quando vem a prensa ou mesmo os fiscalizadores. São códigos criados a partir dessa resistência da classe trabalhadora, uma adaptação constante a uma nova realidade. Estes comportamentos, são de qualquer forma, solidários diante da falta de ofertas de trabalhos, a promessa do crescimento econômico e trabalho descente. Embora os contínuos comentários da pensa, existem muitos vendedores de rua ou "ambulantes" que são muito responsáveis em seus negócios, desde o vendedor de moedas antigas até o vendedor de dozes e bolachas, os mesmos que tem um álcool na mão, máscaras, careta de proteção e até tem sinalizado seu lugar de trabalho no seu espaço reocupado - a rua.

A economia informal foi retrasada em todos os países pela nova pandemia, já que estamos em uma recessão histórica que impacta aos mais vulneráveis, principalmente aos informais como é mencionado no relatório nas metas do ODS $8^{4}$. Os mesmos que foram esquecidos pelos atuais "bonos" à esta classe por não serem formais ou não ter porte de medianas ou grandes empresas. Toda esta reorganização, mas de forma inclusiva e que respeite o grupo trabalhador teve que ser pensada de forma que não existam programas governamentais que impossibilitem o acesso destes benefícios aos mais vulneráveis. Os programas puderam ser planejados em prol do direito à cidade, do genuíno desenvolvimento que inclua emprego produtivo e trabalho decente para todos:

O coronavírus em 2020 causou mudanças abruptas e profundas, retardando ainda mais a economia. Isso está causando um impacto adverso nos mercados de trabalho do mundo, principalmente em trabalhadores informais, trabalhadores por conta própria, assalariados diários e trabalhadores de setores com maior risco de interrupção. De fato, podemos esperar o maior aumento no desemprego global desde a Segunda Guerra Mundial. Ao mesmo tempo, a crise representa uma séria ameaça à segurança e saúde ocupacional dos trabalhadores e pode aumentar o risco de trabalho infantil. São necessárias medidas políticas urgentes para apoiar as empresas, aumentar a demanda de trabalho e preservar os empregos existentes especialmente para os mais vulneráveis - para alcançar emprego pleno e produtivo e trabalho decente para todas as mulheres e homens. (ONU, 2020, p. 40).

\footnotetext{
3 Ver o jornal: https://rpp.pe/lima/actualidad/coronavirus-en-peru-la-victoria-ambulantes-venden-comida-encarretillas-sin-los-minimos-protocolos-de-bioseguridad-noticia-1278848

${ }^{4}$ https://www.un.org/sustainabledevelopment/es/economic-growth/
} 
Os espaços citadinos da capital peruana em tempos pandêmicos possuem dinâmicas peculiares de grandes cidades, onde a economia é movimentada pela informalidade e onde a vida citadina foi voltando aos poucos com a reocupação dos espaços. Embora os esforços das decisões políticas sobre a contenção deste novo vírus estiveram presentes, não foram suficientes para contê-lo, já que sofremos as externalidades da pandemia e nem tanto os efeitos diretos da doença. Desta forma, a pandemia só revelou os problemas de mais de dez anos no sistema, de saúde, de educação, e demais setores. Sendo assim, ainda é necessária a implementação de programas governamentais que além de ser paternalistas, devem ser de assistência social bem planejada pensando na sustentabilidade ao longo do tempo e não apenas que ofereçam "bonos" a uma população que por história, é resistente.

\section{REFERÊNCIAS}

LEFEBVRE, Henri. O direito à cidade. 5 ed. São Paulo: Centauro, 2010.

ONU. The sustainable development goals report 2020. Unites Nations. 2020.

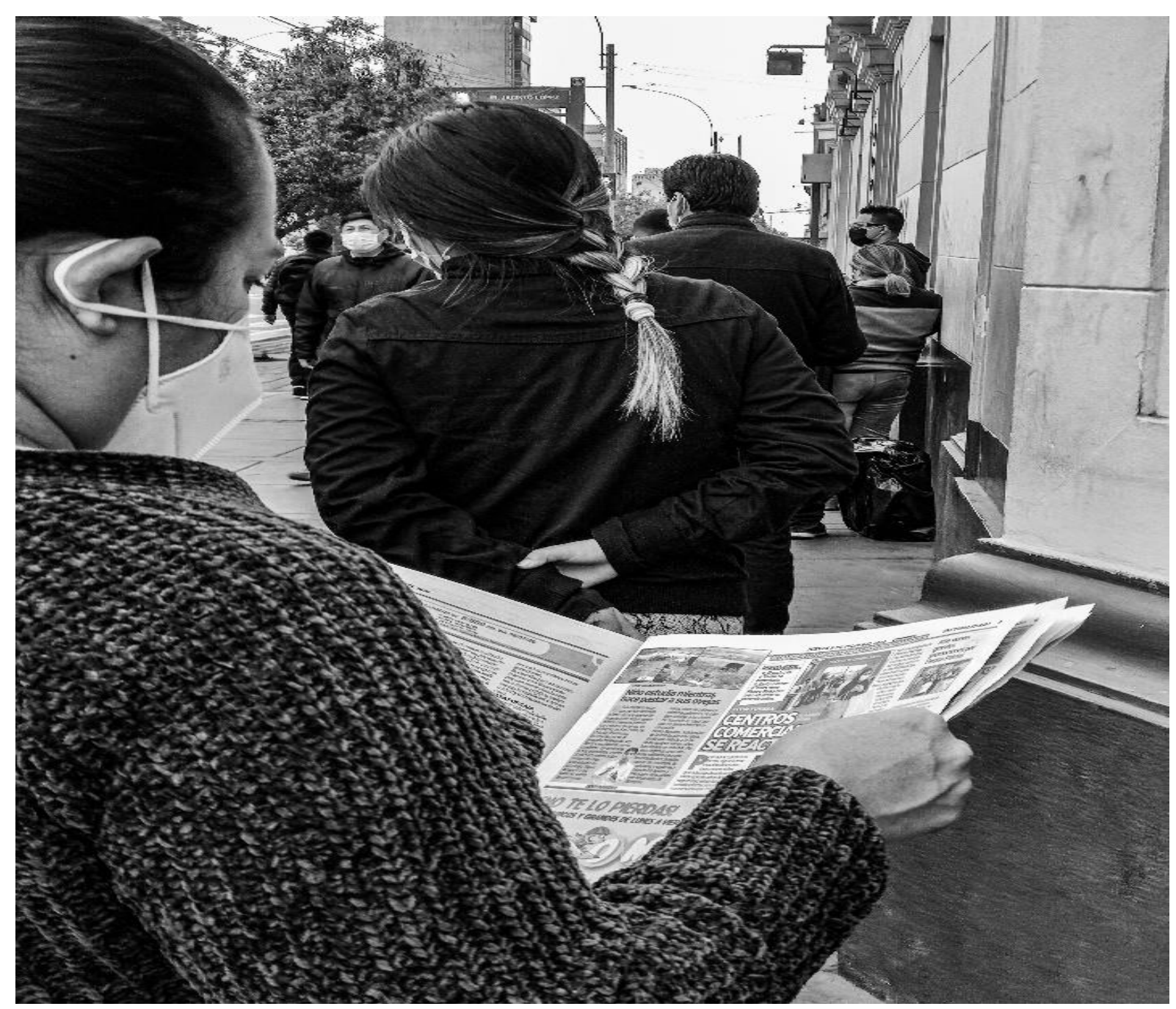



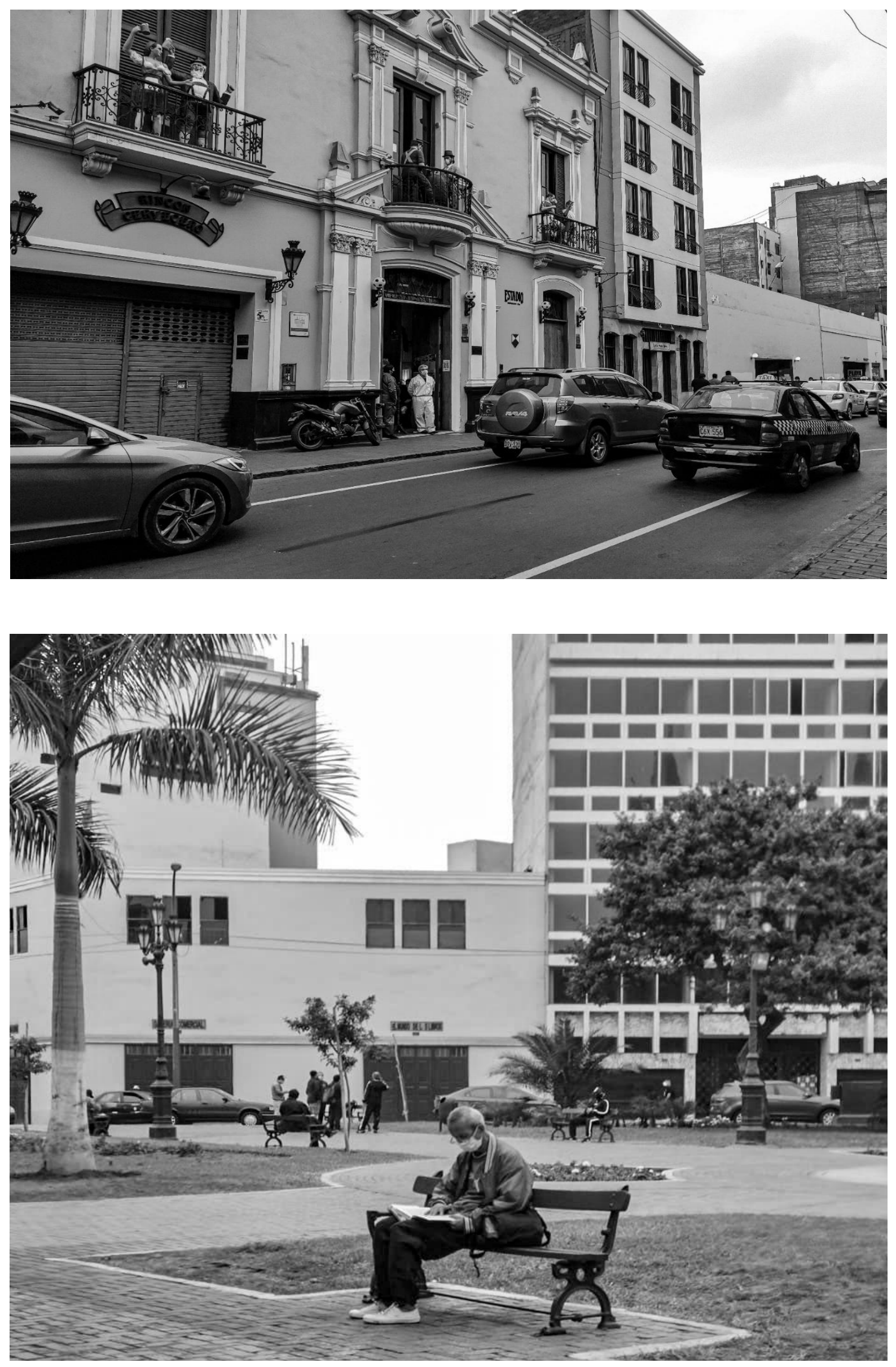

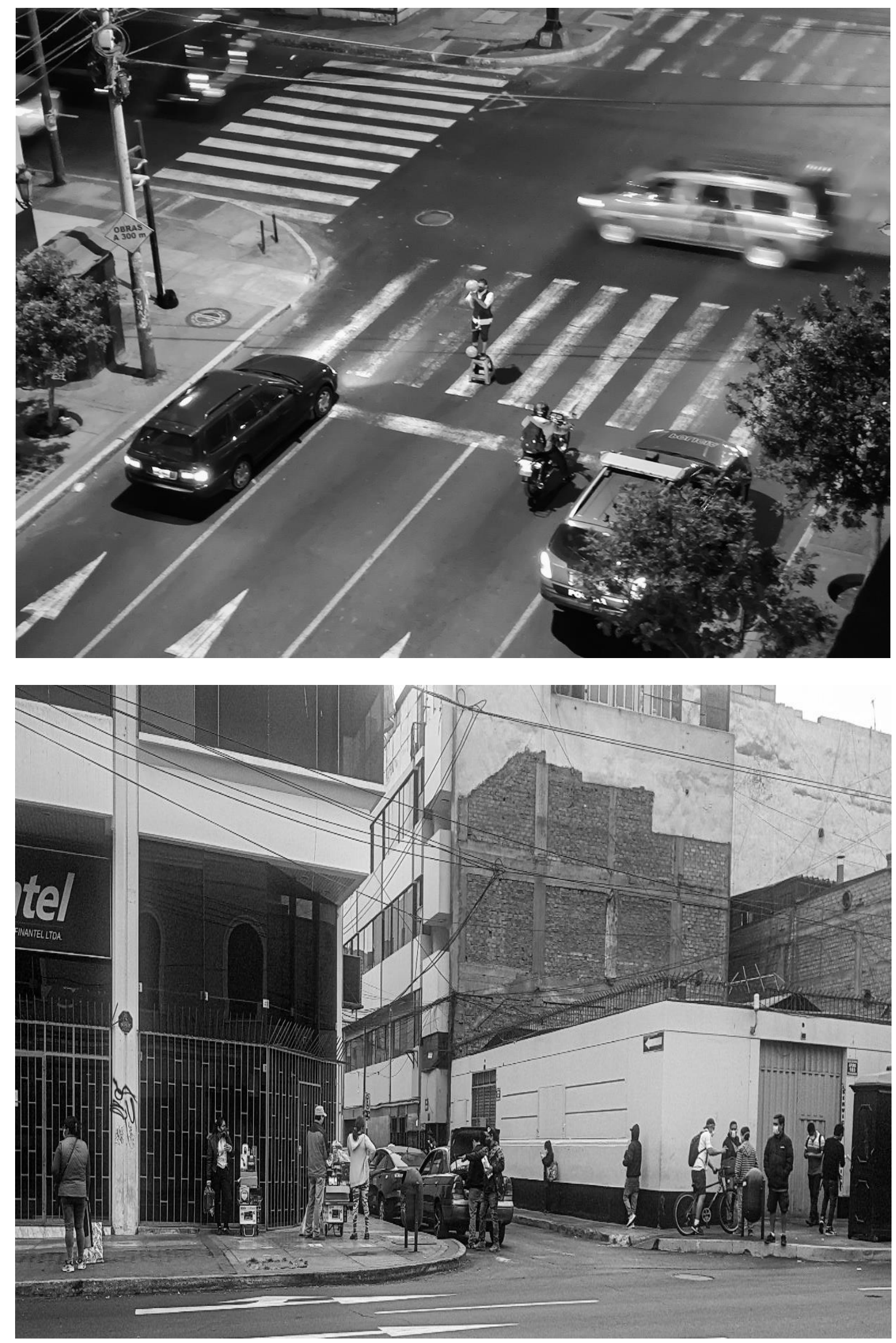

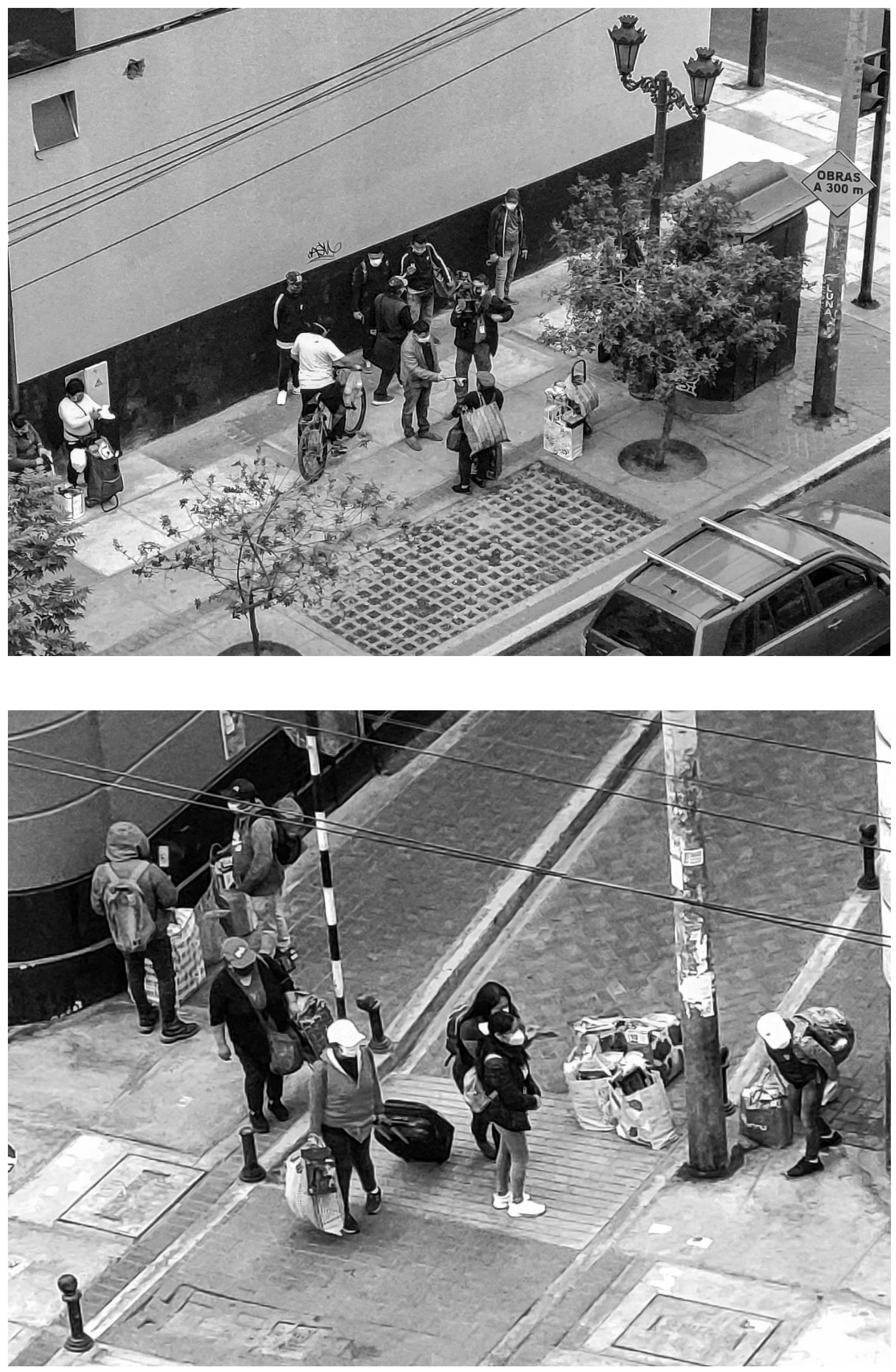

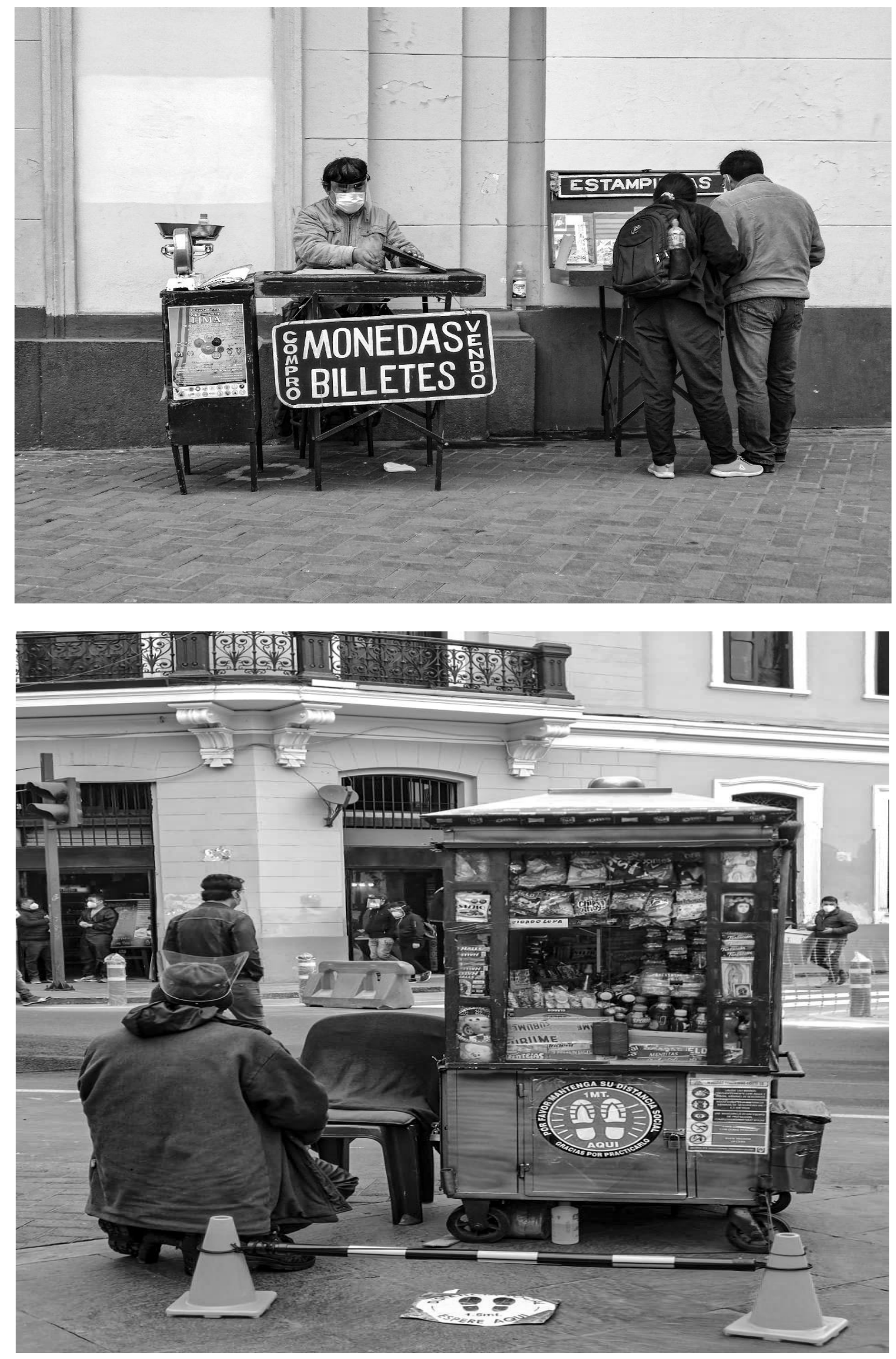